\title{
Two-Phase Flow in Porous Electrodes of Proton Exchange Membrane Fuel Cell
}

\author{
Daokuan Jiao ${ }^{1} \cdot$ Kui Jiao ${ }^{1} \cdot$ Qing $\mathrm{Du}^{1}$
}

Received: 1 January 2020 / Revised: 30 January 2020 / Accepted: 1 February 2020 / Published online: 3 March 2020

(c) The Author(s) 2020

\begin{abstract}
Water management in porous electrodes bears significance due to its strong potential in determining the performance of proton exchange membrane fuel cell. In terms of porous electrodes, internal water distribution and removal process have extensively attracted attention in both experimental and numerical studies. However, the structural difference among the catalyst layer (CL), microporous layer (MPL), and gas diffusion layer (GDL) leads to significant challenges in studying the two-phase flow behavior. Given the different porosities and pore scales of the CL, MPL, and GDL, the model scales in simulating each component are inconsistent. This review emphasizes the numerical simulation related to porous electrodes in the water transport process and evaluates the effectiveness and weakness of the conventional methods used during the investigation. The limitations of existing models include the following: (i) The reconstruction of geometric models is difficult to achieve when using the real characteristics of the components; (ii) the computational domain size is limited due to massive computational loads in three-dimensional (3D) simulations; (iii) numerical associations among 3D models are lacking because of the separate studies for each component; (iv) the effects of vapor condensation and heat transfer on the two-phase flow are disregarded; (v) compressive deformation during assembly and vibration in road conditions should be considered in two-phase flow studies given the real operating conditions. Therefore, this review is aimed at critical research gaps which need further investigation. Insightful potential research directions are also suggested for future improvements.
\end{abstract}

Keywords PEMFC $\cdot$ Porous electrodes $\cdot$ Two-phase flow $\cdot$ Water management

\section{Introduction}

With the ever-increasing environmental consciousness, proton exchange membrane fuel cell (PEMFC) is now considered one of the most promising solutions to future automotive and portable applications due to its high-power density, quick start-up, and zero emissions [1,2]. With the rapid development of material and manufacture technology, the commercialization process of PEMFC vehicles has been largely promoted. The world main stream automotive companies have launched products one after another [3].

A typical PEMFC consists of several main components [4] (Fig. 1), namely bipolar plates which can provide flow channels for reactants and water transport, gas diffusion layer (GDL), catalyst layer (CL), and proton exchange membrane

Qing Du

duqing@tju.edu.cn

1 State Key Laboratory of Engines, Tianjin University, 135 Yaguan Road, Tianjin 300350, China
(PEM). In general, microporous layer (MPL), which is connected with CL and GDL, is adopted to optimize the fuel cell performance. These components provide the whole pathway for heat and mass transfer to ensure the stable operation of a fuel cell to achieve the effective transport of reactants to reaction sites.

PEMFC converts chemical energy to electricity through hydrogen/oxygen electrochemical reaction. The reaction product is environmentally friendly pure water. However, the management of product significantly influences the fuel cell stack performance. Studies regarding water management have been conducted in the past decades [5, 6]. The working principle of PEMFC is as follows: During the reaction, hydrogen and oxygen act as reactants, which are supplied from the anode and cathode inlets to flow channels, respectively. The reactant gases can move into the corresponding $\mathrm{CL}$ through the holes in the porous GDL. Typically, $\mathrm{H}^{+}$on the anode side transports to the cathode side through the PEM and then binds with oxygen ions to form water. Hence, the product (water) is mainly generated on the cathode side. 


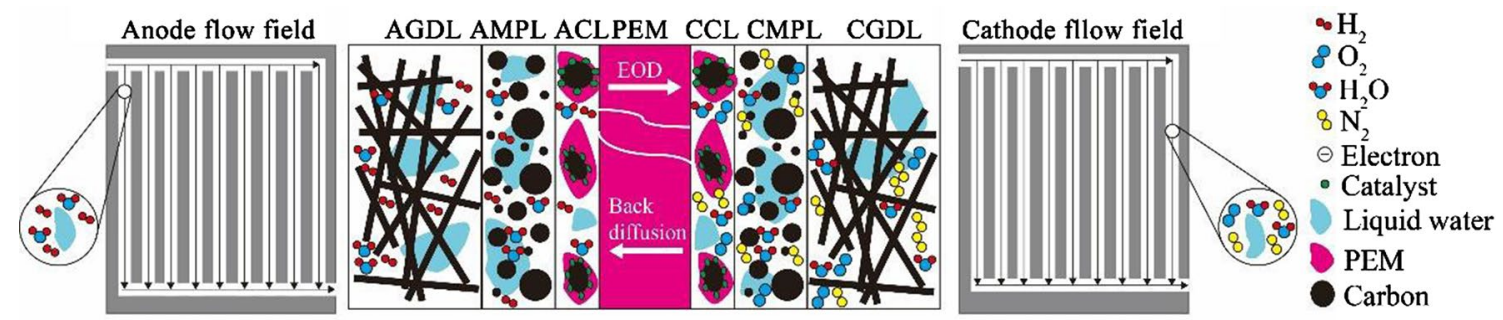

Fig. 1 Schematic of the main components of a PEMFC [4]

Although extremely small amount of water may emerge on the anode side under back-diffusion, most of the excessive water will be removed from the cathode side. The water produced at CL enters MPL, GDL, and gas breathing channels consecutively and is finally removed from the cell.

The three layers in PEMFC all contain porous structures which allow reactants to reach the active area and facilitate water transport to flow channels. CL is placed between the MPL and the membrane. Its structure and components enable three-phase boundary formation, where oxidation-reduction reaction (ORR) occurs to produce water. The water management of cathode CL differs from that of other porous electrodes. Sufficient water is needed to maintain the hydration state of the membrane, which can further enhance ion conductivity. However, excessive water will lead to severe flooding, blocking the reactant transport paths and resulting in performance deterioration [7].

MPL is in contact with CL and applied to the GDL substrate. MPL is generally formed by carbon particles and polytetrafluoroethylene (PTFE), and the thickness ranges from 10 to $100 \mu \mathrm{m}$ with a porosity of $30-50 \%$. The pore size of MPL varies from 0.1 to $0.5 \mu \mathrm{m}$, whereas that of GDL reaches 10-30 $\mu \mathrm{m}$ [8]. Therefore, MPL possesses relatively different porosities, permeability, hydrophobicity, thermal conductivity, and electrical resistance compared with GDL. The addition of MPL to GDL changes transport properties. One of the primary purposes of the MPL is to optimize water transport through the interface between CL and GDL. Weber and Newman [9] have conducted simulations about the roles of MPL in PEMFC. Their results demonstrated an increase in performance when utilizing the MPL. Given the better structural stability which can improve the interface contact, the contact resistance between GDL and CL was reduced. As a result, the oxygen transport was improved and ohmic resistance was reduced. In addition, in water management, MPL acts as a valve that can drive water away from the cathode side and through the membrane to the anode side, thus reducing the risk of water flooding.

GDL is a porous medium that is commonly made from carbon paper or carbon cloth [10]. GDL acts as a gas breathing and water removal path, and it is connected with the flow channel. The two-phase flow behavior inside the GDL significantly influences fuel cell performance. Meanwhile, the pore sizes and fiber diameters of GDL are considerably larger compared with those of MPL and CL. Macro-models and volume of fluid (VOF) are commonly applied to describe internal flow. On the contrary, the numerical methods employed to study two-phase flow in MPLs and CLs are either mesoscopic or microcosmic (Fig. 2).

This review aims to introduce the two-phase flow in porous electrodes in PEMFCs and focuses explicitly on numerical methods. The current research limitations and future outlook are also discussed.

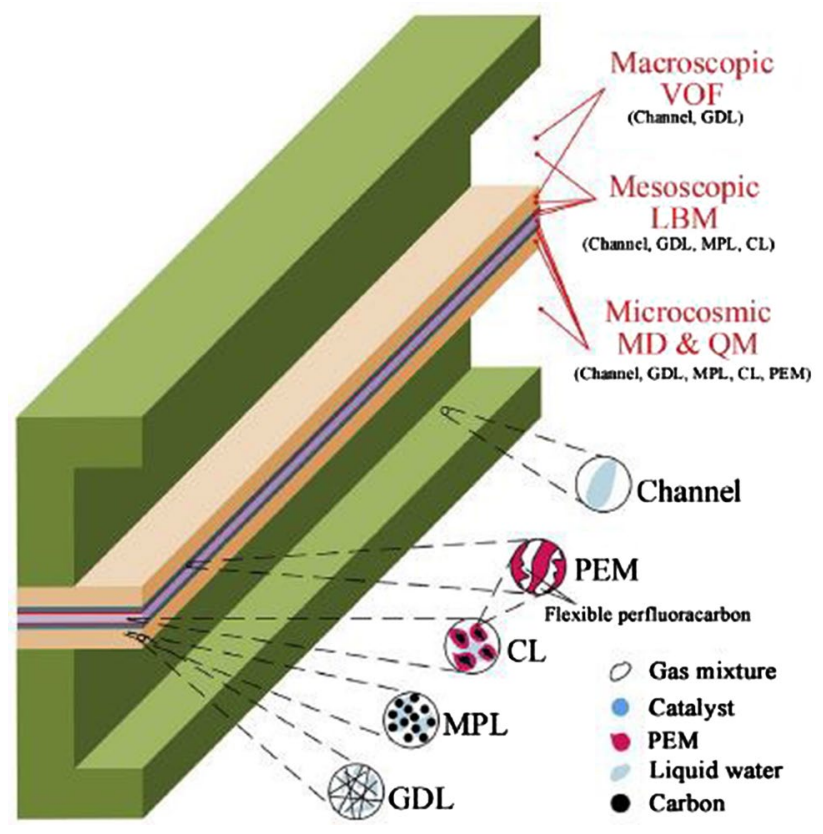

Fig. 2 Schematic of model scales for a PEMFC [4]. Lattice Boltzmann method (LBM), molecular dynamics (MD), and quantum mechanics 


\section{Reconstruction of Porous Electrodes}

The reconstruction of porous electrodes provides the basis for the numerical analysis of heat and mass transfer. In terms of water transport, the reconstructed geometries act as flow paths. Suitable reconstruction methods are required to reflect the real characteristics of porous electrodes to achieve more precise results. Therefore, core parameters, including geometrical properties, porosities, and wettability, should be considered, which poses challenges to reconstruction methods. The reconstruction of porous electrodes also enables the resolution of the limited visualization techniques. When a validated two-phase flow numerical model agrees well with experimental results, parameter studies can be easily conducted.

\section{X-Ray Computed Tomography (X-CT) Method}

Two main methods are used to reconstruct the three-dimensional (3D) structures of porous electrodes [11]: The first is the X-CT method [12-15] which can penetrate non-transparent solid objects to visualize interior features nondestructively. This method obtains digital information of 3D geometries and properties by stacking all contiguous sets of $\mathrm{CT}$ slices. The $3 \mathrm{D}$ reconstructed structure of a tested porous medium sample could be obtained after employing a series of images processing techniques. Then, the geometry could be converted into a computational domain with meshes. This kind of reconstructed geometry can reflect real porous structures. Thus, the effectiveness of the two-phase flow study in porous electrodes will be enhanced. Notably, the reconstruction process within X-CT is based on real material samples. However, the structure of porous electrodes is not homogenous through and in planes. Thus, the reconstructed geometry will be limited by the characteristics of the provided sample, such as the sample size and porosity. In addition, the resolution of X-CT is inadequate to satisfy a full-scale electrode. Material boundaries may also be blurry due to the finite resolution. Furthermore, X-CT will not be an ideal choice when investigating the effect of critical parameters, for instance, various porosities and pore sizes, on two-phase flow.

\section{Stochastic Method}

The second reconstruction technique works by employing the stochastic method [16-18]. The working principle is the application of known properties of a porous medium (e.g., fibrous diameter in GDL), combining the expected target statistical parameters (porosity and layer thickness) based on the stochastic method to generate a porous structure. The vital parameters could be adjusted as desired. For example, a GDL can be reconstructed with different preset fiber diameters and diversiform porous properties. Each parameter can be adjusted independently to conveniently explore the effect of a specified parameter. Given its fast reconstruction and low cost, the stochastic method is commonly used to study the two-phase flow in porous media. However, given the complicated skeleton distributions and random pore shapes, adopting this technique causes difficulty in achieving the real information of a porous media. The numerical results of stochastic method models can be further validated with the X-CT results. In this manner, a suitable reconstruction method with a good prediction capability could be achieved for a specific investigation.

Carbon paper GDL comprises different carbon fibrous layers with a fiber diameter of less than $10 \mu \mathrm{m}$. The gap between fibers mostly forms the pores in GDL, and the size ranges from dozens to hundreds of micrometers. The reconstruction of GDL hence follows reasonable simplifications. Carbon fiber is often considered a long straight cylinder and randomly distributed in a plane to form a single layer [10]. Along the GDL thickness direction, staggered overlapping fibers are ignored among layers, whereas penetration is allowed in each. The diameter of fibers in a single layer remains the same. The binder and PTFE are also ignored in the fibrous reconstruction process. With the superposition of layers, a reconstructed GDL will be obtained. In addition, given the PTFE distribution on the fiber surface, the reconstruction of PTFE will be based on the former GDL. The PTFE contents in each layer will be calculated from the total desired mass/volume fraction inside the GDL. Then, the grids near the fiber surfaces are determined numerically to reconstruct PTFE with probability distribution.

The reconstruction of MPL differs from that of GDL because the carbon particles in MPL are considerable smaller than those of the fibers in GDL [8]. The particles at the nanoscale result in a small porous structure that is unsuitable for macro design. Moreover, the MPL and GDL are not entirely separate. The partial overlapping of MPL and GDL results in reconstruction difficulties. Given the different scales of MPL and GDL, a considerable number of computational grids are required to resolve reconstruction difficulties. Several experimental results indicate that the product liquid (water) is only transported via the MPL cracks $[19,20]$. This finding provides a reasonable simplification for MPL reconstruction. Thus, only the macro-cracks are considered in two-phase flow studies [8].

Compared with the reconstruction of MPL and GDL, the reconstruction of CL is more difficult on account of its multi-scale nature. The $\mathrm{CL}$ consists of a complex mixture of catalysts $(\mathrm{Pt} / \mathrm{C})$, polymer electrolytes, and pores which range from the nanoscale to microscale. With the limitation of computational loads, the properties of reconstructed CL 
are with partial simplifications. For example, the $\mathrm{Pt} / \mathrm{C}$ and polymer electrolytes are considered as a whole. Siddique and Liu [21] employed a controlled quasi-random algorithm to reconstruct the $\mathrm{CL}$ with an approximate real structure. Chen et al. [22] managed to obtain the nanoscale structures of CL by adopting the quartet structure generation set (QSGS) method. The reconstruction processes were consistent with the experimental fabrication process, including the steps from carbon seed generation, carbon phase growth, and $\mathrm{Pt}$ deposition to ionomer coverage.

\section{Two-Phase Flow in Porous Electrodes}

Liquid water accumulation in PEMFC can be detected using visualization techniques, including nuclear magnetic resonance imaging [23, 24], neutron imaging [25, 26], electron microscopy [27, 28], X-ray [29, 30], and direct optical photography [31, 32]. Given the traditional optical testing devices, for instance, high-speed cameras, the incident light ray cannot penetrate the completely opaque bipolar, GDL, and other components of PEMFC. Therefore, numerous challenges arise in the attempts to research water transport in in situ working PEMFC. Direct optical visualization holds the potential to obtain high spatial and temporal resolution in water transporting as flow channels and external GDL layers. Nevertheless, this condition only becomes possible when the materials of PEMFC components are transparent. Review papers have extensively introduced the application and working principles regarding the use of liquid water visualization techniques in PEMFC. Meanwhile, the capacities and limitations have also been summarized [33].

Water is mainly produced on the cathode side of the CL and transported from MPL and GDL to flow channels [34]. During the process, the pore sizes range from the nanometer to millimeter scale. Given the considerable scale difference among layers, the two-phase flow in porous electrodes is simulated separately. Thus far, studies only consider a single layer at a time to investigate the water behavior in 3D simulations (Table 1).

\section{Two-Phase Flow in CL}

Water is produced when ORR occurs at the three-phase boundary. The water inside the CL layer should remain sufficient to keep the membrane hydrated to enhance ionic conductivity on the one hand, whereas excessive water should be removed to avoid blocking of gas transport on the other. Water transport processes in the cathode CL are categorized as (i) water transport from the membrane to the $\mathrm{CL}$ due to electroosmosis, (ii) back-diffusion effect, (iii) condensation and evaporation of water, and (iv) water removal through MPL and GDL to channels [35].

In the past decades, many efforts have been focused on the CL structural design, material improvement, and the decrease in Pt loading [36]. The role of the CL in water balance has never been investigated in depth, either experimentally or numerically. On the contrary, the effects of GDL and flow channels on water transport have been broadly studied, and the research is still active. For example, studies explored novel flow channel designs to improve fuel cell performance $[3,37]$.

In situ visualization of water flooding in the CL is challenging. Limited studies have been performed on water transport in the CL. Nguyen et al. [38] measured capillary properties using in situ neutron imaging but with certain limitation. Only the positive capillary pressure was measured, and the data were scattered due to the resolution or other experimental processing errors. Kusoglu et al. [39] conducted experiments to examine the CL water uptake, that is, the transport of liquid water into the pore and vapor into the ionomer. The author reported that the most significant

Table 1 Two-phase flow in porous electrodes

\begin{tabular}{|c|c|c|}
\hline Porous electrodes & Reconstruction methods & Two-phase flow study \\
\hline CL & $\begin{array}{l}\text { (1) Controlled quasi-random algorithm } \\
\text { [21] } \\
\text { (2) QSGS [22] }\end{array}$ & $\begin{array}{l}\text { Transport and physical processes [35] } \\
\text { (1) Electroosmotic } \\
\text { (2) Back-diffusion } \\
\text { (3) Water condensation/evaporation } \\
\text { (4) Water transport to MPL/GDL }\end{array}$ \\
\hline MPL & Stochastic model (cracks) [8] & $\begin{array}{l}\text { (1) Effects of MPL thickness, porosity, pore size, and hydrophobicity } \\
\text { [47] } \\
\text { (2) Role of MPL cracks }[8,19,20,47] \\
\text { (3) Back-diffusion }[46,47]\end{array}$ \\
\hline GDL & $\begin{array}{l}\text { (1) X-CT [12-15] } \\
\text { (2) Stochastic model [16-18] }\end{array}$ & $\begin{array}{l}\text { (1) Effects of GDL materials [69-71], porosities [10, 72, 73], and PTFE } \\
\text { treatment [74-79] } \\
\text { (2) GDL structural modification: MPL [8], groove, and perforation } \\
\text { [80-88] } \\
\text { (3) Structural deformation: compression [91-98] }\end{array}$ \\
\hline
\end{tabular}


effect was whether the sample was cracked. In addition, the relationship between capillary pressure and saturation was measured.

Numerical and theoretical studies related to water transport in the CL are available in Ref. [35]. However, most of them focused on water flooding in the GDL or flow channel instead of specifically addressing water transport in the $\mathrm{CL}$ [40]. These studies assumed that the CL layer is extremely thin, and water is produced at the CL/GDL interface which is also incorrect. Das et al. [35] derived simplified 1D mathematical formulations from the conservations of mass and momentum equations to analyze water transport in the $\mathrm{CL}$ and considered the above four water transport processes. Ferreira et al. [34] proposed a 1D +3D numerical model, where the cathode CL was simplified to a 1D computational domain. Modeling the whole cathode porous electrodes will result in extremely high computational costs due to the massive grid numbers from distinct model scales. Furthermore, in the above studies, the CLs were not reconstructed due to the 1D simplified assumptions. Chen et al. [22] reconstructed the CL structure; however, the macroscopic transport properties rather than two-phase flow were their research interests. The effective diffusivity of oxygen and the effective conductivity of protons were investigated employing LBM.

The statistical pore size distribution in the CL is around a few tens of nanometers. The model scale is more significant than the generation of water molecules. Given the complicated vapor/liquid flow state of water in the CL, a more reasonable model should be developed. Currently, the twophase flow of water/vapor or water/air is frequently ignored in numerical assumptions [41, 42].

\section{Two-Phase Flow in MPL}

The introduction of MPL into the GDL substrate has been proven to improve the performance of PEMFC. The pore scale of the MPL is larger than that of the CL and smaller than that of the GDL. Therefore, compared with a GDL without MPL, a hydraulic barrier is formed due to the hydrophobic MPL. The water produced in the CL needs to overcome a high pressure to penetrate the MPL. In this way, the hydration state of membrane is maintained, especially in dry conditions. By contrast, gas diffusion from the GDL to CL through the MPL will also cause challenges to the same extent. The design of the MPL structure should seek balance to achieve the best PEMFC performance.

Several researchers observed that the MPL promotes water transport from the CL to the GDL. Gostick et al. [43] suggested that due to the MPL percolation effect, the GDL saturation will significantly reduce when water breakthrough occurs. Lu et al. [44] noted that the MPL not only limits the number of water breakthrough location but also helps form stable water transport paths. However, other researchers argued that due to water back-diffusion, the MPL impedes fuel cell performance [45, 46]. Consequently, the effects of the MPL on water transport remain to be elucidated. The dispute focuses on whether the MPL will increase or hinder back-diffusion and the role of MPL cracks [47]. The effect of MPL properties, including thickness, porosity, pore size distribution, and hydrophobicity modifications, on PEMFC performance has been discussed [47-52]. An experimental method was mainly employed in the above studies. Most of the results indicate that the MPL can be beneficial to the PEMFC performance, but the observation of water transport inside MPL is insufficient.

The difficulties of GDL reconstruction with MPL have been discussed in previous chapter. In terms of diameter, carbon fiber in the GDL is a hundred times larger than the carbon black in the MPL. The computational requirement is still beyond the present when considering the combination of real MPL and GDL structures. Several experimental studies reported that water leaves the interface of CL/ MPL in vapor form [53-56]; therefore, the influence of the MPL on water flow should be minimal [57-59]. Other researchers suggested that the liquid water produced in $\mathrm{CL}$ is removed from MPL cracks to GDL and not from the extremely small MPL pores [19, 20]. For MPL cracks, their scale sizes are considerably larger compared with MPL pores. Therefore, in the two-phase flow study, researchers can only reconstruct the MPL cracks $(5-15 \mu \mathrm{m})$, which serve as the liquid water removal pathway. Deng et al. [8] employed an optimized stochastic model to reconstruct the GDL microstructure with MPL and then adopted a 3D two-phase LBM to investigate water transport inside the GDL/MPL (Fig. 3). The authors suggested that the insertion of the MPL increases the breakthrough pressure. With the MPL cracks as liquid water breakthrough paths, the water transport process in GDL will start from the macro-cracks. Hence, the interface between GDL and MPL is unblocked; water flooding will be relieved. Although valuable quantitative and qualitative results have been obtained to explain water transport through the MPL cracks, the reconstruction of MPL cracks in various studies lacked elaboration. Given the manufacturing process, drying process, and heat treatment, the cracks were irregular in shape and inhomogeneous in dimension (length, width, and depth). The precise reconstruction of the MPL requires high-resolution experimental results. In addition, MPL and GDL are not wholly separate parts; the overlapping part between MPL and GDL should be treated more accurately. Therefore, the reconstruction processes of GDL with MPL result in considerable difficulties, which are unfavorable for the study of two-phase flow. Given that the stochastic method cannot provide sufficient details on the reconstructed MPL structures, the X-CT method may 
Fig. 3 a Reconstructed GDL microstructures with MPL [8], b 2D slice showing the reconstructed MPL cracks [8] and scanning electron microscopy (SEM) result of realistic MPL [60]

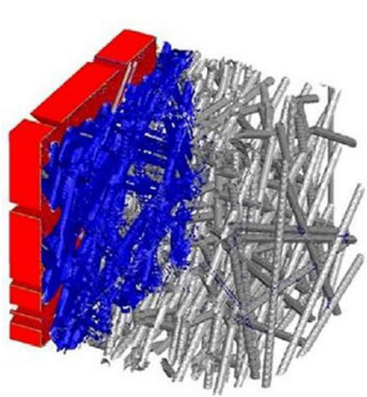

(a)

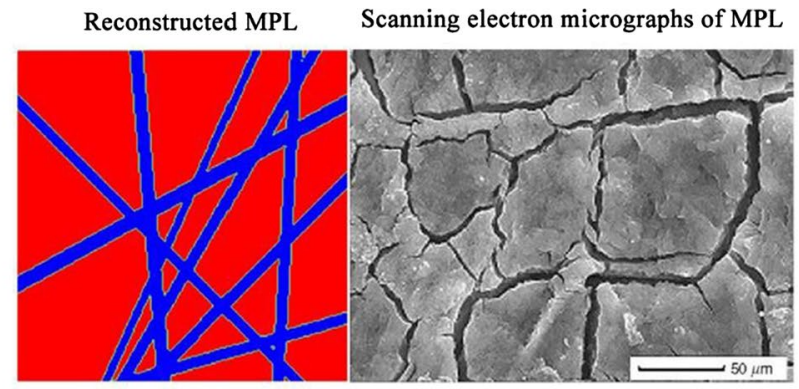

(b) be a better option to employ. Although the resolution of the X-CT method is currently limited, it is still promising due to its fast development.

\section{Two-Phase Flow in GDL}

Intensive research has addressed water transport in the GDL compared with the other porous electrodes [61, 62]. GDLs act not only as water and reactant gas transport paths but also providing passage for electron and mechanical support for membrane electrode assembly (MEA) [63, 64]. In terms of water management, GDL plays a crucial role in maintaining the delicate balance between water removal and membrane hydration [65-68].

From the perspective of literature studies on water management in GDL, experimentally, and numerically, the research interests can be categorized into three classes.

First, the effects of GDL properties, including GDL material, porosity, and PTFE treatment, on water management were investigated. Both experimental and numerical approaches have been employed to study the material effects on water management [69-71]. Studies indicated that the manufacture materials may affect the GDL porosities, pore sizes, and pore distributions. Specifically, the key parameter of a porous media is porosity, which primarily influences water transport. The stochastic method was adopted to reconstruct the GDL microstructure of Toray carbon papers with experimentally determined varying porosities
[10]. In the through-plane direction, the porosity was large at the two poles and low in the middle distribution. Water transport in the GDL has also been investigated using VOF methods, laminar flow, and no-phase change assumptions. Zhan et al. [72] suggested that the GDL water saturation was reduced when gradient porosities were applied on the GDL. This linear change in porosity was also examined by Huang et al. [73]. The author developed a 3D, two-phase, non-isothermal model to investigate the effect of porosity gradient in the cathode GDL on fuel cell performance. The capillary diffusivity and oxygen usage were discussed. GDL will largely improve water management with treatment using PTFE, which is a hydrophobic agent. With PTFE coating, the initial pore size was altered in addition to the change in surface wettability. The effects of PTFE treatment and PTFE content have been extensively discussed in recent years [74-79].

Second, the effects of structural modification, including regular fibrous layers with/without MPL and the modification of groove and perforation on a porous GDL, on water management have been investigated [80-88]. In the previous section, the addition of MPL has been introduced in detail. Several studies also attempted to perforate the GDL at specific locations to improve water transport. Owing to the differences in local porosities and hydrophobicity, a prior path for water removal will be formed. The utilization of groove and perforation on the path will absorb water from the surrounding pores due to capillary
Fig. 4 a SEM image of a laser treatment-perforated GDL [89], b $2 \mathrm{D}$ slices showing the effect of perforation depths on water distribution in the GDL [90]

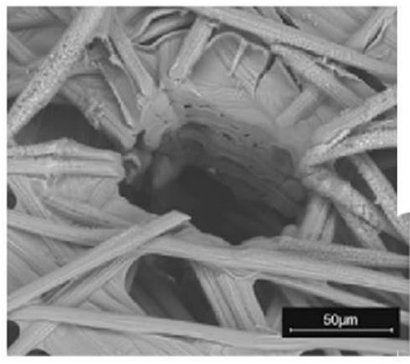

(a)

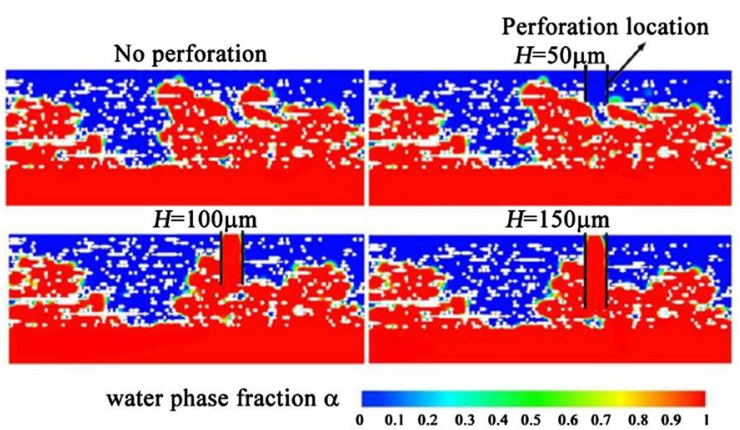

(b) 
pressure and then promote water removal. Alink et al. [89] investigated a laser treatment GDL where a perforation zone was formed (Fig. 4). Water transport in the GDL was examined employing the environmental scanning electron microscope (ESEM). By condensing the water inside the GDL or introducing an external pressure difference, water intrusion could occur, which could then be visualized by the ESEM. The observed results suggest that a perforated GDL may promote the in-plane water transport toward the hole. However, the hole was hydrophilic due to the loss of PTFE in that area during the heating process. Thus, the hole could act as a fast water removal path into the gas channel. Niu et al. [90] numerically studied the two-phase flow in a perforated GDL employing stochastic and VOF methods. The effects of perforation locations, depths, and diameters were considered. The authors suggested that the perforation location should be close to the water breakthrough points to facilitate water removal.

Third, the effects of structural deformation on water management were investigated. During preloading and assembly, the GDL suffered deformation due to the clamping pressure [91-98]. The compression of the GDL reduced the porosity. Experimental approaches showed that water saturation in the compressed GDL is higher compared with the uncompressed ones. Zenyuk et al. [99] tested the compression samples with X-ray techniques and observed that local water saturation differed significantly in the GDL under land and channel locations. Recently, Zhou et al. [100] carried out a numerical simulation adopting finite element and VOF methods to investigate water transport in a compressed GDL (Fig. 5). Various compression ratios were considered, and quantitative correlations between capillary pressure and water saturation have been given for compressed/uncompressed GDL. The GDL was reconstructed using the stochastic method, after which the reconstructed structure was processed, adopting the finite element method to solve the compression. Finally, water transport was studied employing the VOF method by applying various pressure gradients on boundaries.
However, the computational domain size was insufficient compared with the realistic GDL, and the MPL was not considered in the study.

\section{Summary}

Water management plays a significant role in improving the PEMFC performance. Seeking a balance between membrane hydration and the effective removal of excessive water is the expected target for water management. In terms of porous electrodes, experimental and numerical studies have been conducted to investigate the two-phase flow behavior. The numerical method can explore in depth the roles of porous electrodes in water management. The main reconstruction methods, namely X-CT and the stochastic methods, were introduced and compared. The advantages and limitations of these methods were exhaustively discussed. From the CL to the GDL, the pore sizes range from nanometer to millimeter scale. Given the considerable scale difference among layers, the two-phase flow in porous electrodes is simulated separately. Most studies only considered a single layer at a time to investigate water behavior in 3D simulation. Therefore, this paper mainly focused on the evaluation of the effectiveness and weakness of conventional numerical methods during the investigation. The limitations of existing models include the following:

(i) The reconstruction of geometric models, especially that of the CL and MPL, to fully achieve a realistic characteristic of components is difficult.

(ii) The computational domain size is limited due to the massive computational loads in 3D simulation. A small 3D partial model with real CL, MPL, and GDL structures is still beyond the computational capacity.

(iii) For 3D models, the separate studies on each component resulted in the lack of numerical associations among them; the porous electrodes in 1D models contain numerous simplifications.
Fig. 5 a Schematic of the GDL deformation under clamping pressure, b VOF model results of water transport in GDL samples with different clamping pressures [100]

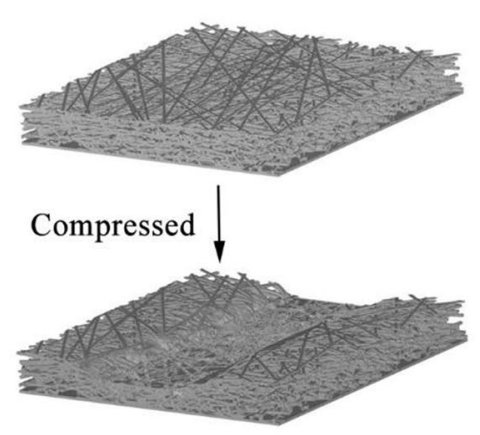

(a)

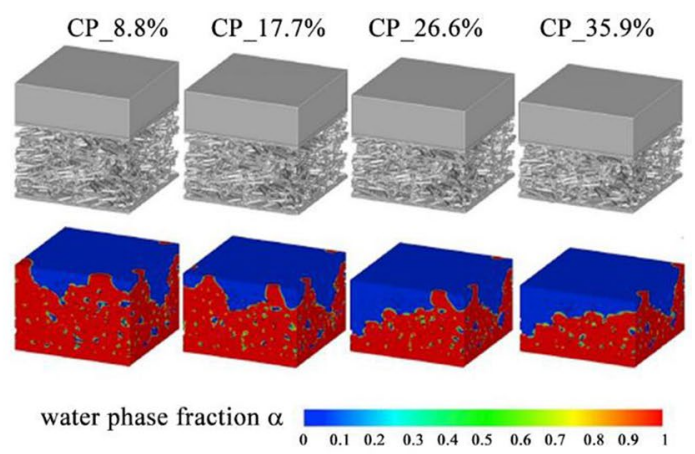

(b) 
(iv) Most of the current studies were conducted with an isothermal assumption. The effects of vapor condensation and heat transfer on the two-phase flow were ignored.

(v) Given the real operating conditions, the compressive deformation during assembly and vibration in road conditions should also be considered in two-phase flow studies.

\section{Outlook}

Future studies should optimize geometry models by adopting a suitable reconstruction method to achieve universal results. When porous electrodes are studied separately, close numerical associations should be adopted in the boundary conditions, whereas precise geometry connections should be adopted in the modeling when they are studied in combination. Given the computational capacity, a 1D, 2D, and 3D partial/integral coupled model could be developed. According to the literature, water in the GDL can be in liquid/ vapor forms. Hence, a comprehensive model that couples two-phase flow with condensation/conduction heat transfer models should be brought forward for better water management. This comprehensive model should consider the real operating conditions, including the compressive deformation during assembly and vibration in road conditions (Table 2).

Furthermore, the novel structures of porous electrodes need to be developed to satisfy the requirement of future high-power performance fuel cells. As for the CL, with ultra-low Pt loading, the performance loss should be controlled at high current density conditions. Instead of conventional carbon powder-based CL, researchers have designed high-efficient CL using vertically aligned carbon nanotubes, which are highly ordered and possess porous structures [101, 102]. Apart from the stable Pt dispersion and high electrical conductivity, the designed structure should meet the free transport of oxygen and water.

In terms of the GDL, several water management issues are related to conventional flow channels [103]. Except for the uneven distribution of the reactants and temperature in conventional bipolar plates, the excessive water naturally accumulates due to the existence of ribs, especially at high current density. Studies replaced the functions of flow channels with new types of flow fields, for instance, porous metallic powder [104] and metal foam [105]. These novel flow fields take advantage of the uniform distribution of the reactants and efficient removal of water but are easily subject to corrosion. Recently, Park et al. [106] proposed a GDL/flow-field unified MEA using graphene foam, which is similar to metal foam. The thickness of MEA was largely reduced due to the elimination of the GDL, and the cell performance was improved. Therefore, the two-phase flow inside these novel designs should be further studied.

Liquid water management stems from the low working temperature $\left(60-80^{\circ} \mathrm{C}\right)$, and water flooding could be avoided if the operating temperature is over $100{ }^{\circ} \mathrm{C}$. An appropriate increase in the temperature to improve fuel cell performance may result in membrane dehydration and decomposition. Notably, this feature depends on the development of future membrane materials and properties (Table 2).

Therefore, this review aimed at key research gaps in which further investigations are needed. Potential research directions were suggested also for future improvements.

Table 2 Research limitations and future outlook of two-phase flow in porous electrodes

\begin{tabular}{|c|c|c|}
\hline Porous electrodes & Research limitations & Future outlook \\
\hline $\begin{array}{l}\text { CL } \\
\text { MPL GDL }\end{array}$ & $\begin{array}{l}\text { Experimental methods } \\
\text { (1) Low spatial resolution [21] } \\
\text { (2) Unavailable to study the sole effect of a parameter } \\
\text { (3) In situ visualization is difficult [38] } \\
\text { Reconstruction } \\
\text { (1) Difficult to achieve the } \\
\text { real characteristics [10, 61] } \\
\text { (2) Small computational domain [8,100] } \\
\text { (3) The enormous structural difference; separate reconstruc- } \\
\text { tion [21, 90] } \\
\text { (4) Simplify MPL to cracks [8] } \\
\text { Numerical methods } \\
\text { (1) Computational capacity } \\
\text { (2) Separate studies [22, 62] } \\
\text { (3) Simplify CL to 1D model [34, 35] } \\
\text { (4) Simply MPL to cracks [8] } \\
\text { (5) Ignore the geometry deformation; compression [99, 100] } \\
\text { (6) Ignore the vapor condensation [10] } \\
\text { (7) Ignore the heat transfer effect [74] } \\
\text { (8) Ignore the road vibration conditions }\end{array}$ & $\begin{array}{l}\text { Methods improvement } \\
\text { (1) More advanced visualization techniques } \\
\text { (2) Combined X-CT with the stochastic model } \\
\text { (3) Numerical associations among electrodes in modeling } \\
\text { (1) } 1 \mathrm{D}+2 \mathrm{D}+3 \mathrm{D} \text { coupled model } \\
\text { (2) Developing a comprehensive model coupled two-phase } \\
\text { flow with the condensation and heat transfer } \\
\text { Future design } \\
\text { (1) High-efficient CL with highly ordered and porous struc- } \\
\text { tures [101, 102] } \\
\text { (2) New types of flow fields, } \\
\text { porous metallic powder [104], and metal foam [105] } \\
\text { (3) GDL/flow-field unified MEA [106] } \\
\text { (4) Higher operating temperature PEMFC to avoid water } \\
\text { flooding }\end{array}$ \\
\hline
\end{tabular}


Acknowledgements The study was supported by the National Natural Science Foundation of China (No. 51676135) and the National Key Research and Development Program of China (No. 2018YFB0105505).

Open Access This article is licensed under a Creative Commons Attribution 4.0 International License, which permits use, sharing, adaptation, distribution and reproduction in any medium or format, as long as you give appropriate credit to the original author(s) and the source, provide a link to the Creative Commons licence, and indicate if changes were made. The images or other third party material in this article are included in the article's Creative Commons licence, unless indicated otherwise in a credit line to the material. If material is not included in the article's Creative Commons licence and your intended use is not permitted by statutory regulation or exceeds the permitted use, you will need to obtain permission directly from the copyright holder. To view a copy of this licence, visit http://creativecommons.org/licenses/by/4.0/.

\section{References}

1. Ji MB, Wei ZD (2009) A review of water management in polymer electrolyte membrane fuel cells. Energies 2(4):1057-1106

2. Luo YQ, Jiao K (2018) Cold start of proton exchange membrane fuel cell. Prog Energy Combust Sci 64:29-61

3. Kim J, Luo G, Wang CY (2017) Modeling two-phase flow in three-dimensional complex flow-fields of proton exchange membrane fuel cells. J Power Sources 365:419-429

4. Zhang GB, Jiao K (2018) Multi-phase models for water and thermal management of proton exchange membrane fuel cell: a review. J Power Sources 391:120-133

5. Liu X, Guo H, Ma CF (2006) Water flooding and two-phase flow in cathode channels of proton exchange membrane fuel cells. J Power Sources 156(2):267-280

6. Qin CZ, Hassanizadeh SM (2015) A new approach to modelling water flooding in a polymer electrolyte fuel cell. Int J Hydrogen Energy 40(8):3348-3358

7. Stumper J, Löhr M, Hamada S (2005) Diagnostic tools for liquid water in PEM fuel cells. J Power Sources 143(1-2):150-157

8. Deng H, Hou YZ, Jiao K (2019) Lattice Boltzmann simulation of liquid water transport inside and at interface of gas diffusion and micro-porous layers of PEM fuel cells. Int J Heat Mass Transf 140:1074-1090

9. Weber AZ, Newman J (2005) Effects of microporous layers in polymer electrolyte fuel cells. J Electrochem Soc 152(4):A677

10. Niu ZQ, Wang Y, Jiao K et al (2018) Two-phase flow dynamics in the gas diffusion layer of proton exchange membrane fuel cells: volume of fluid modeling and comparison with experiment. J Electrochem Soc 165(9):F613-F620

11. Fadzillah DM, Rosli MI, Talib MZM et al (2017) Review on microstructure modelling of a gas diffusion layer for proton exchange membrane fuel cells. Renew Sustain Energy Rev 77:1001-1009

12. Gao Y, Hou Z, Wu XY et al (2018) The impact of sample size on transport properties of carbon-paper and carbon-cloth GDLs: direct simulation using the lattice Boltzmann model. Int J Heat Mass Transf 118:1325-1339

13. Jinuntuya F, Whiteley M, Chen R et al (2018) The effects of gas diffusion layers structure on water transportation using X-ray computed tomography based Lattice Boltzmann method. J Power Sources 378:53-65

14. García-Salaberri PA, Hwang G, Vera M et al (2015) Effective diffusivity in partially-saturated carbon-fiber gas diffusion layers: effect of through-plane saturation distribution. Int J Heat Mass Transf 86:319-333

15. Bednarek T, Tsotridis G (2017) Calculation of effective transport properties of partially saturated gas diffusion layers. J Power Sources 340:111-120

16. Hao L, Cheng P (2009) Lattice Boltzmann simulations of anisotropic permeabilities in carbon paper gas diffusion layers. $\mathrm{J}$ Power Sources 186(1):104-114

17. Schulz VP, Becker J, Wiegmann A et al (2007) Modeling of two-phase behavior in the gas diffusion medium of PEFCs via full morphology approach. J Electrochem Soc 154(4):B419

18. Tayarani-Yoosefabadi Z, Harvey D, Bellerive J et al (2016) Stochastic microstructural modeling of fuel cell gas diffusion layers and numerical determination of transport properties in different liquid water saturation levels. J Power Sources 303:208-221

19. Sasabe T, Deevanhxay P, Tsushima S et al (2011) Soft X-ray visualization of the liquid water transport within the cracks of micro porous layer in PEMFC. Electrochem Commun 13(6):638-641

20. Wargo EA, Schulz VP, Çeçen A et al (2013) Resolving macroand micro-porous layer interaction in polymer electrolyte fuel cells using focused ion beam and X-ray computed tomography. Electrochim Acta 87:201-212

21. Siddique NA, Liu FQ (2010) Process based reconstruction and simulation of a three-dimensional fuel cell catalyst layer. Electrochim Acta 55(19):5357-5366

22. Chen L, Wu G, Holby EF et al (2015) Lattice Boltzmann porescale investigation of coupled physical-electrochemical processes in $\mathrm{C} / \mathrm{Pt}$ and non-precious metal cathode catalyst layers in proton exchange membrane fuel cells. Electrochim Acta 158:175-186

23. Tsushima S, Teranishi K, Hirai S (2005) Water diffusion measurement in fuel-cell SPE membrane by NMR. Energy 30(2-4):235-245

24. Feindel KW, Bergens SH, Wasylishen RE (2006) The use of $1 \mathrm{H}$ NMR microscopy to study proton-exchange membrane fuel cells. Chem Phys Chem 7(1):67-75

25. Satija R, Jacobson DL, Arif M et al (2004) In situ neutron imaging technique for evaluation of water management systems in operating PEM fuel cells. J Power Sources 129(2):238-245

26. Kramer D, Lehmann E, Frei G et al (2005) An on-line study of fuel cell behavior by thermal neutrons. Nucl Instrum Methods Phys Res Sect A Accel Spectrom Detect Assoc Equip 542(1-3):52-60

27. Nam JH, Kaviany M (2003) Effective diffusivity and water-saturation distribution in single- and two-layer PEMFC diffusion medium. Int J Heat Mass Transf 46(24):4595-4611

28. Lim C, Wang CY (2004) Effects of hydrophobic polymer content in GDL on power performance of a PEM fuel cell. Electrochim Acta 49(24):4149-4156

29. Lee SJ, Lim NY, Kim S et al (2008) X-ray imaging of water distribution in a polymer electrolyte fuel cell. J Power Sources 185(2):867-870

30. Manke I, Hartnig C, Grünerbel M et al (2007) Investigation of water evolution and transport in fuel cells with high resolution synchrotron X-ray radiography. Appl Phys Lett 90(17):174105

31. Tüber K, Pócza D, Hebling C (2003) Visualization of water buildup in the cathode of a transparent PEM fuel cell. J Power Sources 124(2):403-414

32. Hakenjos A, Muenter H, Wittstadt U et al (2004) A PEM fuel cell for combined measurement of current and temperature distribution, and flow field flooding. J Power Sources 131(1-2):213-216

33. Bazylak A (2009) Liquid water visualization in PEM fuel cells: a review. Int J Hydrogen Energy 34(9):3845-3857 
34. Ferreira RB, Falcão DS, Oliveira VB et al (2017) 1D + 3D twophase flow numerical model of a proton exchange membrane fuel cell. Appl Energy 203:474-495

35. Das PK, Li XG, Liu ZS (2010) Analysis of liquid water transport in cathode catalyst layer of PEM fuel cells. Int J Hydrogen Energy 35(6):2403-2416

36. Kongkanand A, Subramanian NP, Yu YC et al (2016) Achieving high-power PEM fuel cell performance with an ultralow-Ptcontent core-shell catalyst. ACS Catal 6(3):1578-1583

37. Bao ZM, Niu ZQ, Jiao K (2019) Analysis of single- and twophase flow characteristics of 3-D fine mesh flow field of proton exchange membrane fuel cells. J Power Sources 438:226995

38. Nguyen TV, Lin GY, Ohn H et al (2006) Measurements of twophase flow properties of the porous media used in PEM fuel cells. ECS Trans 3:415-423

39. Kusoglu A, Kwong A, Clark KT et al (2012) Water uptake of fuel-cell catalyst layers. J Electrochem Soc 159(9):F530-F535

40. Ding YL, Bi XT, Wilkinson DP (2013) 3D simulations of the impact of two-phase flow on PEM fuel cell performance. Chem Eng Sci 100:445-455

41. Wang GQ, Mukherjee PP, Wang CY (2006) Direct numerical simulation (DNS) modeling of PEFC electrodes. Electrochim Acta 51(15):3139-3150

42. Lange KJ, Sui PC, Djilali N (2010) Pore scale simulation of transport and electrochemical reactions in reconstructed PEMFC catalyst layers. J Electrochem Soc 157(10):B1434

43. Gostick JT, Ioannidis MA, Fowler MW et al (2009) On the role of the microporous layer in PEMFC operation. Electrochem Commun 11(3):576-579

44. Lu ZJ, Daino MM, Rath C et al (2010) Water management studies in PEM fuel cells, part III: dynamic breakthrough and intermittent drainage characteristics from GDLs with and without MPLs. Int J Hydrogen Energy 35(9):4222-4233

45. Kadowaki K, Tabe Y, Chikahisa T (2011) Role of microporous layer for water transfer phenomena in PEFC. ECS Trans 41(1):431-438

46. Pasaogullari U, Wang CY (2004) Two-phase transport and the role of micro-porous layer in polymer electrolyte fuel cells. Electrochim Acta 49(25):4359-4369

47. Omrani R, Shabani B (2017) Gas diffusion layer modifications and treatments for improving the performance of proton exchange membrane fuel cells and electrolysers: a review. Int J Hydrogen Energy 42(47):28515-28536

48. Chen J, Xu HF, Zhang HM et al (2008) Facilitating mass transport in gas diffusion layer of PEMFC by fabricating microporous layer with dry layer preparation. J Power Sources 182(2):531-539

49. Ismail MS, Borman D, Damjanovic T et al (2011) On the through-plane permeability of microporous layer-coated gas diffusion layers used in proton exchange membrane fuel cells. Int J Hydrogen Energy 36(16):10392-10402

50. Orogbemi OM, Ingham DB, Ismail MS et al (2016) The effects of the composition of microporous layers on the permeability of gas diffusion layers used in polymer electrolyte fuel cells. Int J Hydrogen Energy 41(46):21345-21351

51. Ismail MS, Damjanovic T, Ingham DB et al (2010) Effect of polytetrafluoroethylene-treatment and microporous layercoating on the electrical conductivity of gas diffusion layers used in proton exchange membrane fuel cells. J Power Sources 195(9):2700-2708

52. Burheim OS, Su HN, Pasupathi S et al (2013) Thermal conductivity and temperature profiles of the micro porous layers used for the polymer electrolyte membrane fuel cell. Int J Hydrogen Energy 38(20):8437-8447
53. Thomas A, Maranzana G, Didierjean S et al (2014) Thermal and water transfer in PEMFCs: investigating the role of the microporous layer. Int J Hydrogen Energy 39(6):2649-2658

54. Ito H, Heo Y, Ishida M et al (2017) Application of a self-supporting microporous layer to gas diffusion layers of proton exchange membrane fuel cells. J Power Sources 342:393-404

55. Owejan JP, Owejan JE, Gu WB et al (2010) Water transport mechanisms in PEMFC gas diffusion layers. J Electrochem Soc 157(10):B1456

56. Aoyama Y, Suzuki K, Tabe Y et al (2014) Observation of water transport in the micro-porous layer of a polymer electrolyte fuel cell with a freezing method and cryo-scanning electron microscope. Electrochem Commun 41:72-75

57. Blanco M, Wilkinson DP (2014) Investigation of the effect of microporous layers on water management in a proton exchange membrane fuel cell using novel diagnostic methods. Int J Hydrogen Energy 39(29):16390-16404

58. Malevich D, Halliop E, Peppley BA et al (2009) Investigation of charge-transfer and mass-transport resistances in PEMFCs with microporous layer using electrochemical impedance spectroscopy. J Electrochem Soc 156(2):B216

59. Deevanhxay P, Sasabe T, Tsushima S et al (2013) Effect of liquid water distribution in gas diffusion media with and without microporous layer on PEM fuel cell performance. Electrochem Commun 34:239-241

60. Wang XL, Zhang HM, Zhang JL et al (2006) Micro-porous layer with composite carbon black for PEM fuel cells. Electrochim Acta 51(23):4909-4915

61. Yin Y, Wu TT, He P et al (2014) Numerical simulation of twophase cross flow in microstructure of gas diffusion layer with variable contact angle. Int J Hydrogen Energy 39(28):15772-15785

62. Niu ZQ, Jiao K, Wang Y et al (2018) Numerical simulation of two-phase cross flow in the gas diffusion layer microstructure of proton exchange membrane fuel cells. Int J Energy Res 42(2):802-816

63. Barbir F (2013) Main cell components, material properties, and processes. PEM Fuel Cells, 2nd edn. Elsevier, Amsterdam, pp $73-117$

64. Jayakumar A, Sethu SP, Ramos M et al (2015) A technical review on gas diffusion, mechanism and medium of PEM fuel cell. Ionics 21(1): $1-18$

65. Holmström N, Ihonen J, Lundblad A et al (2007) The influence of the gas diffusion layer on water management in polymer electrolyte fuel cells. Fuel Cells 7(4):306-313

66. Nguyen TV (2006) Water management by material design and engineering for PEM fuel cells. ECS Trans 3(1):1171. https://doi. org/10.1149/1.2356236

67. Koresawa R, Utaka Y (2014) Improvement of oxygen diffusion characteristic in gas diffusion layer with planar-distributed wettability for polymer electrolyte fuel cell. J Power Sources 271:16-24

68. Selamet OF, Pasaogullari U, Spernjak D et al (2011) In situ twophase flow investigation of proton exchange membrane (PEM) electrolyzer by simultaneous optical and neutron imaging. ECS Trans 41(1):349-362

69. Spernjak D, Prasad AK, Advani SG (2007) Experimental investigation of liquid water formation and transport in a transparent single-serpentine PEM fuel cell. J Power Sources 170(2):334-344

70. Hussain N, van Steen E, Tanaka S et al (2017) Metal based gas diffusion layers for enhanced fuel cell performance at high current densities. J Power Sources 337:18-24

71. Natarajan D, Nguyen TV (2003) A two-dimensional, two-phase, multicomponent, transient model for the cathode of a proton exchange membrane fuel cell using conventional gas distributors. J Electrochem Soc 150(3):L5 
72. Zhan Z, Xiao J, Zhang Y et al (2007) Gas diffusion through differently structured gas diffusion layers of PEM fuel cells. Int J Hydrogen Energy 32(17):4443-4451

73. Huang YX, Cheng CH, Wang XD et al (2010) Effects of porosity gradient in gas diffusion layers on performance of proton exchange membrane fuel cells. Energy 35(12):4786-4794

74. Niu ZQ, Bao ZM, Wu JT et al (2018) Two-phase flow in the mixed-wettability gas diffusion layer of proton exchange membrane fuel cells. Appl Energy 232:443-450

75. Flückiger R, Marone F, Stampanoni M et al (2011) Investigation of liquid water in gas diffusion layers of polymer electrolyte fuel cells using X-ray tomographic microscopy. Electrochim Acta 56(5):2254-2262

76. Shimpalee S, Beuscher U, van Zee JW (2007) Analysis of GDL flooding effects on PEMFC performance. Electrochim Acta 52(24):6748-6754

77. Prasanna M, Ha HY, Cho EA et al (2004) Influence of cathode gas diffusion media on the performance of the PEMFCs. J Power Sources 131(1-2):147-154

78. Qi ZG, Kaufman A (2002) Improvement of water management by a microporous sublayer for PEM fuel cells. J Power Sources 109(1):38-46

79. Soler J, Hontañón E, Daza L (2003) Electrode permeability and flow-field configuration: influence on the performance of a PEMFC. J Power Sources 118(1-2):172-178

80. Lu Z, Waldecker J, Xie X et al (2013) Investigation of water transport in perforated gas diffusion layer by neutron radiography. ECS Trans 58(1):315-324

81. Manahan MP, Clement JT, Srouji AK et al (2014) Laser modified fuel cell diffusion media: engineering enhanced performance via localized water redistribution. J Electrochem Soc 161(10):F1061-F1069

82. Haußmann J, Markötter H, Alink R et al (2013) Synchrotron radiography and tomography of water transport in perforated gas diffusion media. J Power Sources 239:611-622

83. Markötter H, Alink R, Haußmann J et al (2012) Visualization of the water distribution in perforated gas diffusion layers by means of synchrotron X-ray radiography. Int J Hydrogen Energy 37(9):7757-7761

84. Gerteisen D, Sadeler C (2010) Stability and performance improvement of a polymer electrolyte membrane fuel cell stack by laser perforation of gas diffusion layers. J Power Sources 195(16):5252-5257

85. Okuhata G, Tonoike T, Nishida K et al (2013) Effect of perforation structure of cathode GDL on liquid water removal in PEFC. ECS Trans 58(1):1047-1057

86. Manahan MP, Mench MM (2012) Laser perforated fuel cell diffusion media: engineered interfaces for improved ionic and oxygen transport. J Electrochem Soc 159(7):F322-F330

87. Gerteisen D, Heilmann T, Ziegler C (2008) Enhancing liquid water transport by laser perforation of a GDL in a PEM fuel cell. J Power Sources 177(2):348-354

88. Alink R, Haußmann J, Markötter H et al (2013) The influence of porous transport layer modifications on the water management in polymer electrolyte membrane fuel cells. J Power Sources 233:358-368

89. Alink R, Gerteisen D, Mérida W (2011) Investigating the water transport in porous media for PEMFCs by liquid water visualization in ESEM. Fuel Cells 11(4):481-488

90. Niu ZQ, Wu JT, Bao ZM et al (2019) Two-phase flow and oxygen transport in the perforated gas diffusion layer of proton exchange membrane fuel cell. Int J Heat Mass Transf 139:58-68

91. Fazeli M, Hinebaugh J, Fishman Z et al (2016) Pore network modeling to explore the effects of compression on multiphase transport in polymer electrolyte membrane fuel cell gas diffusion layers. J Power Sources 335:162-171
92. Le AD, Zhou B (2008) A general model of proton exchange membrane fuel cell. J Power Sources 182(1):197-222

93. Bao N, Zhou YB, Jiao K et al (2014) Effect of gas diffusion layer deformation on liquid water transport in proton exchange membrane fuel cell. Eng Appl Comput Fluid Mech 8(1):26-43

94. Satjaritanun P, Hirano S, Shum AD et al (2018) Fundamental understanding of water movement in gas diffusion layer under different arrangements using combination of direct modeling and experimental visualization. J Electrochem Soc 165(13):F1115-F1126

95. Jeon DH, Kim H (2015) Effect of compression on water transport in gas diffusion layer of polymer electrolyte membrane fuel cell using lattice Boltzmann method. J Power Sources 294:393-405

96. Han CL, Chen ZQ (2019) Numerical simulations of two-phase flow in a proton-exchange membrane fuel cell based on the generalized design method. Energy Sources Part A Recover Util Environ Eff 41(10):1253-1271

97. Tranter TG, Burns AD, Ingham DB et al (2015) The effects of compression on single and multiphase flow in a model polymer electrolyte membrane fuel cell gas diffusion layer. Int J Hydrogen Energy 40(1):652-664

98. Chippar P, Kyeongmin O, Kang K et al (2012) A numerical investigation of the effects of GDL compression and intrusion in polymer electrolyte fuel cells (PEFCs). Int J Hydrogen Energy 37(7):6326-6338

99. Zenyuk IV, Parkinson DY, Hwang G et al (2015) Probing water distribution in compressed fuel-cell gas-diffusion layers using X-ray computed tomography. Electrochem Commun 53:24-28

100. Zhou X, Niu ZQ, Bao ZM et al (2019) Two-phase flow in compressed gas diffusion layer: finite element and volume of fluid modeling. J Power Sources 437:226933

101. Tian ZQ, Lim SH, Poh CK et al (2011) A highly order-structured membrane electrode assembly with vertically aligned carbon nanotubes for ultra-low Pt loading PEM fuel cells. Adv Energy Mater 1(6):1205-1214

102. Kongkanand A, Mathias MF (2016) The priority and challenge of high-power performance of low-platinum proton-exchange membrane fuel cells. J Phys Chem Lett 7(7):1127-1137

103. Tseng CJ, Tsai BT, Liu ZS et al (2012) A PEM fuel cell with metal foam as flow distributor. Energy Convers Manag 62:14-21

104. Kariya T, Hirono T, Funakubo H et al (2014) Effects of the porous structures in the porous flow field type separators on fuel cell performances. Int J Hydrogen Energy 39(27):15072-15080

105. Tsai BT, Tseng CJ, Liu ZS et al (2012) Effects of flow field design on the performance of a PEM fuel cell with metal foam as the flow distributor. Int J Hydrogen Energy 37(17):13060-13066

106. Park JE, Lim J, Lim MS et al (2019) Gas diffusion layer/flowfield unified membrane-electrode assembly in fuel cell using graphene foam. Electrochim Acta 323:134808

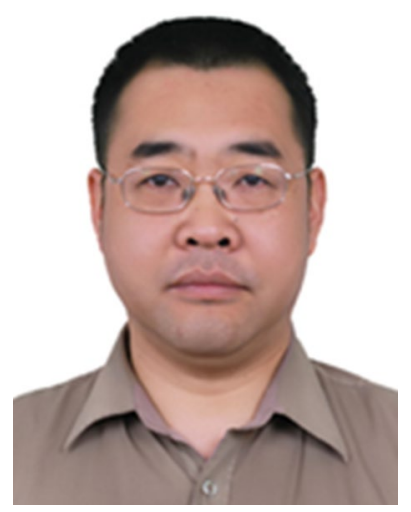

Qing Du received his Ph.D. in School of Mechanical Engineering in Tianjin University in 1998. After his Ph.D. study, he had his postdoctoral training in State Key Laboratory of Engines, Tianjin University, and became a full professor in 2006 in the same institute. His current research focuses on water and heat management in fuel cell, including simulation and experimental study in this area. 